\title{
Desenvolvimentos recentes na gestão dos recursos humanos nos países-membros da $\mathrm{OCDE}^{*}$
}

\author{
Serviço de Gestão Públical \\ Comitê de Gestão Pública - PUMA/OCDE
}

Revista do

Serviço

Público

Ano 52

Número 2

Abr-Jun 2001

\section{Introdução}

Os governos da OCDE se comprometeram, no decorrer das duas últimas décadas, com reformas de gestão pública ambiciosas. Estas reformas têm como objeto principal a Gestão dos Recursos Humanos (GRH). Uma das razões fundamentais destas reformas é a recessão econômica, que repercutiu profundamente no mundo inteiro nos anos 80 e no começo dos anos 90. A recessão econômica exigiu uma importante reestruturação, tanto do setor público quanto do setor privado. A maioria dos países-membros da OCDE começou a repensar o papel do Estado e o modo de prestação de serviços pelo setor público. Com efeito, o modo de prestação de serviços pelo setor público deu lugar a numerosas críticas com relação à sua falta de eficiência e de confiança nas instituições do Estado.

A Gestão de Recursos Humanos (GRH), um dos instrumentos mais importantes da administração estratégica, transformou-se num dos principais pontos da reforma. Os poderes públicos, ao introduzir um grande leque de novos mecanismos ou ao modificar os sistemas existentes, deram grande prioridade à melhoria da produtividade da função pública e à sua melhor receptividade para com as necessidades dos clientes.

As experiências vividas pelos governos dos países-membros da OCDE nos permitem identificar as seguintes orientações de reforma:

- As diferenças de Gestão de RH atenuaram-se entre os setores público e privado. A eficiência econômica foi um dos critérios mais importantes de reforma, como também a redução dos efetivos das administrações públicas.

- Numerosos esforços foram empregados para conceder aos ministérios maior flexibilidade e maior liberdade na GRH, adotando diversas medidas de descentralização e de delegação.

Organização para a Cooperação e o Desenvolvimento Econômico (OCDE), Paris, França.

Contato: www.oecd.org/ contact/

Traduzido por René Loncan Net 
- Em troca dessa maior flexibilidade e maior independência concedidas às agências administrativas, os governos buscaram tornar os ministérios e/ou os quadros operacionais mais responsáveis na Gestão de RH, insistindo nas performances e na ética da função pública.

- Por sua parte, os governos também estabeleceram como prioridade transformarem-se em empregadores modelos.

Apesar destas orientações comuns, nem todos os países aplicaram as mesmas reformas. O ritmo e a amplitude das reformas da GRH são muito diferentes de um país para outro, devido a suas estratégias de reformas globais, a seus aprendizados culturais e históricos e a seu nível de recessão econômica. Os países-membros da OCDE adotaram estratégias de reformas da GRH que cobrem um amplo leque. Numa das extremidades deste leque, situam-se as reformas mais vastas, que transformaram fundamentalmente a natureza do emprego na função pública e a GRH. O exemplo mais explícito é o caso da Nova Zelândia, que não dispõe de uma legislação regendo o estatuto do emprego nem de um código de trabalho que se aplique especificamente aos funcionários públicos. As disposições jurídicas são idênticas para o setor público e o setor privado. Vários outros países também poderiam, embora em um nível inferior, enquadrar-se nesta categoria. Trata-se, particularmente, da Austrália, do Reino Unido, da Suíça e da Suécia.

Em compensação, na outra extremidade, situa-se um grupo de países nos quais as reformas da GRH foram muito mais restritas, onde os sistemas tradicionais (e com freqüência centralizados) e os princípios da GRH não foram, praticamente, objeto de modificações. As reformas realizadas por estes países foram "baseadas em projetos" que respondiam às preocupações individuais da GRH.

Diferentes dosagens destas situações extremas podem ser observadas entre estes dois pólos. Reformas de grande proporção estão em curso na Holanda, em outros países nórdicos e, numa extensão menor, no Canadá e nos Estados Unidos; entretanto, em vários outros países da Europa Meridional, as reformas são mais baseadas na modernização e na racionalização dos mecanismos de gestão de pessoal do que na integração de novas teorias de gestão. Estes países também adotaram reformas que recorrem mais aos concursos e aos procedimentos de entrada mais centralizados, a fim de promover dispositivos de lotação de pessoal mais racionais e justos, baseados no mérito individual.

No entanto, a orientação das questões da Gestão de RH modificouse sensivelmente ao longo dos últimos anos. Os países-membros da OCDE enfrentam, no momento, uma série de desafios diferentes no novo ambiente administrativo do século XXI. Com a redução do mercado de trabalho, o recrutamento e a manutenção do pessoal de alta qualidade nas administrações públicas constituem, atualmente, um problema importante na maioria dos países-membros. Estes últimos insistiram na necessidade de promover a capacidade de direção dos funcionários do Estado, a fim de melhorar a 
integridade e os valores da função pública. As mudanças e a gestão do conhecimento também constituem, atualmente, uma questão urgente.

Quando examinamos as raízes profundas destes novos desafios que se colocam para a GRH, fica muito claro que eles emanam, numa certa proporção, das reformas anteriores relativas à gestão dos recursos humanos. É por isso que é indispensável, para entender em que posição estamos e qual é a natureza destes novos desafios, que se examine as iniciativas de reforma anteriores dos países-membros da OCDE, com relação à GRH. O presente relatório visa, então, descrever as evoluções das reformas da GRH que nós encontramos nos países-membros e estabelecer uma conexão com as reformas anteriores em relação aos desafios atuais. O relatório se apóia, principalmente, nos estudos prévios da OCDE e em dois outros estudos que examinam os recentes desenvolvimentos da gestão dos recursos humanos, promovidos pela OCDE em 1999 e em 2000. Nós nos reportaremos, igualmente, às discussões que tiveram lugar na Reunião do Grupo de Trabalho e na Reunião dos Peritos sobre a GRH, bem como aos relatórios que foram apresentados na ocasião.

\section{Redução das diferenças de Gestão de RH entre os setores público e privado}

Ao longo da década de 90, uma das características mais marcantes das reformas das administrações públicas foi a introdução, no setor público, de diversos mecanismos do tipo comercial, ${ }^{1}$ que se baseavam na hipótese de que as administrações públicas podiam atingir a eficiência máxima funcionando como uma empresa. ${ }^{2}$ Em vários setores, os serviços foram privatizados, comercializados ou repassados a prestadores de serviços de fora do setor público. Neste sentido, numerosas regulamentações que governavam as administrações públicas sofreram inúmeras modificações, o que reduziu ou ocultou as diferenças entre o emprego no setor público e o emprego no setor privado. Esta tendência fez com que uma parte importante dos cargos das administrações públicas fosse eliminada na busca de uma maior eficiência econômica.

\section{O estatuto do emprego e a segurança do emprego}

Nos países-membros, os empregados do Estado eram, já há algum tempo, regidos pelo regime de uma legislação especial (lei sobre o serviço público, legislações e regulamentos gerais do serviço público, lei nacional sobre a função pública etc.). Neste contexto, uma das normas básicas é o emprego permanente; assim sendo, as relações profissionais são muito 
diferentes entre os setores público e privado. Contudo, esta tradição de longa data vem atravessando um período de mutação importante desde o final dos anos 80. Alguns países introduziram uma certa flexibilidade em sua legislação, e seus contratos de duração determinada começaram a ampliar-se. No que diz respeito aos estatutos do emprego, as diferenças entre o setor público e o setor privado começaram a atenuar-se em vários países-membros. Por isso, a grande segurança do emprego, que era reconhecida como um dos privilégios dos postos da administração, defronta-se, hoje em dia, com sérios desafios. A Tabela 1 ilustra esta evolução nos diversos países da OCDE.

\section{Tabela 1: A análise comparativa dos estatutos de emprego ${ }^{3}$}

\begin{tabular}{|c|c|c|}
\hline Temas & Norma & Países \\
\hline \multirow[t]{2}{*}{$\begin{array}{l}\text { 1. Estatuto jurídico } \\
\text { de emprego (Regula- } \\
\text { mentos diferentes } \\
\text { para os setores } \\
\text { público e privado) }\end{array}$} & Sim & $\begin{array}{l}\text { Austrália, Canadá, } \\
\text { Finlândia, França, } \\
\text { Hungria, Japão, } \\
\text { Holanda, Polônia, Suíça } \\
\text { e Estados Unidos }\end{array}$ \\
\hline & Não & Nova Zelândia \\
\hline \multirow{4}{*}{$\begin{array}{l}\text { 2. Segurança do } \\
\text { emprego (em relação } \\
\text { ao setor privado) }\end{array}$} & Garantia de emprego & Japão \\
\hline & $\begin{array}{l}\text { Demissão difícil mas } \\
\text { possível }\end{array}$ & França e Polônia \\
\hline & $\begin{array}{l}\text { Demissão possível } \\
\text { em condição particulares }\end{array}$ & $\begin{array}{l}\text { Canadá, Finlândia, } \\
\text { Hungria, Noruega, } \\
\text { Holanda e Estado } \\
\text { Unidos }\end{array}$ \\
\hline & $\begin{array}{l}\text { Alinhamento às práticas } \\
\text { do setor privado }\end{array}$ & $\begin{array}{l}\text { Austrália, Nova } \\
\text { Zelândia e Suíça }\end{array}$ \\
\hline \multirow[t]{2}{*}{ 3. Empregador } & $\begin{array}{l}\text { Ministérios e agências } \\
\text { administrativas }\end{array}$ & $\begin{array}{l}\text { Austrália, Finlândia, } \\
\text { Hungria, Nova Zelândia } \\
\text { Noruega, Holanda, } \\
\text { Polônia e Estados } \\
\text { Unidos }\end{array}$ \\
\hline & Órgão central & $\begin{array}{l}\text { Canadá, França, } \\
\text { Japão e Suíça }\end{array}$ \\
\hline \multirow[t]{3}{*}{ 4. Tipos de emprego } & $\begin{array}{l}\text { Emprego vitalício, com } \\
\text { duração determinada }\end{array}$ & França, Japão e Polônia \\
\hline & $\begin{array}{l}\text { Permanente, com } \\
\text { duração determinada }\end{array}$ & $\begin{array}{l}\text { Austrália, Canadá, } \\
\text { Finlândia, Hungria, } \\
\text { Nova Zelândia, } \\
\text { Noruega, Holanda e } \\
\text { Estados Unidos }\end{array}$ \\
\hline & $\begin{array}{l}\text { Com duração } \\
\text { determinada }\end{array}$ & Suíça \\
\hline
\end{tabular}


Segundo o estudo da OCDE, que envolveu 12 países, cada um deles dispõe de uma legislação que rege os estatutos do emprego e de um código do trabalho específico do setor público. A única exceção aos países que figuram na Tabela 1 é a Nova Zelândia. Naquele país, os dois setores seguem as mesmas disposições jurídicas, à exceção de algumas disposições suplementares que se aplicam aos serviços públicos, a partir das quais os chefes de departamentos devem seguir com uma política de pessoal em harmonia com o princípio do "bom empregador". No caso, os empregados do setor público são tratados como os empregados do setor privado. A Suécia, que não constava no estudo, aplica um quadro jurídico análogo.

Os empregados do setor público gozam, tradicionalmente, de maior segurança de emprego que os empregados do setor privado. Os resultados do estudo mostram que a França e o Japão aplicam, todavia, políticas tradicionais, sendo a segurança do emprego geralmente garantida aos empregados do setor público. Nestes dois países, o empregador não pode rescindir um contrato de trabalho por razões econômicas que levem a cortes de cargos. Quando empregos são suprimidos orçamentariamente, os ajustes se fazem pelo jogo natural das demissões. No entanto, a segurança do emprego não é norma na maioria dos países, onde a demissão é possível em condições peculiares, particularmente no Canadá, na Finlândia, na Hungria, na Noruega, na Holanda e nos Estados Unidos. Além disso, alguns países, como a Austrália, a Nova Zelândia e a Suíça, modificaram sua política de emprego inspirando-se nas práticas do setor privado.

Devido a esta nova tendência, o tipo de emprego foi sensivelmente modificado. Como ilustra a Tabela 1, a garantia de emprego vitalício permanece amplamente praticada na França e no Japão. Mas nos outros países, os contratos permanentes foram progressivamente substituindo os empregos vitalícios. Os contratos com duração determinada também são mais freqüentes.

\section{Redução dos efetivos do setor público}

Vários países-membros aplicam, desde as duas últimas décadas, uma política de redução dos efetivos no setor público, na busca de uma eficiência econômica. Com esta finalidade, duas abordagens diferentes foram adotadas.

- Alguns países implementaram programas de compressão de emprego no setor público. A título de exemplo, a Alemanha dispõe de um plano de redução de pessoal de alto nível que data de antes da reunificação. Este plano, que fixa a taxa de redução anual entre $1 \%$ e $1,5 \%$ levou à eliminação de 17.000 cargos desde 1993. O governo coreano também estabeleceu um plano trienal de redução dos efetivos de funcionários públicos, excluindo os funcionários da polícia e os de ensino, que deverá resultar na eliminação de 26.000 cargos de funcionários, até o final de 2001. 
- Em outros países, a redução dos efetivos resultou da privatização ou de outras reformas que intervieram no estatuto das instituições públicas. Alguns países da OCDE, pela introdução de diversos mecanismos baseados no jogo do mercado nos serviços da administração, reduziram os efetivos de funcionários públicos. Os cargos correspondentes às funções que foram transferidas ao setor privado, seja pela privatização, seja pela prestação externa de serviços, foram suprimidos. Na Finlândia, por exemplo, seis grandes empresas públicas ${ }^{4}$ mudaram de estatuto em 1989/1990, o que se traduziu em uma baixa de $10 \%$ nos empregos do setor público.

Os diversos mecanismos aplicados pelos poderes públicos para reduzir os empregos do setor público são, principalmente, o jogo natural das demissões, as supressões de empregos voluntárias, as transferências, as opções de aposentadoria antecipada, bônus de saída ou combinações diversas destes fatores.

A Tabela 2 ilustra a evolução do emprego, ao longo da última década, em alguns países da OCDE. Consequiência das políticas de redução dos efetivos nos países-membros, o número de empregados do setor público diminuiu de forma importante durante este período, com apenas algumas exceções. As tendências anuais do emprego no setor público revelam importantes reduções de efetivos iniciadas na Finlândia, em Luxemburgo, na Suécia e no Reino Unido em 1993, na Austrália, na Itália e na Suécia em 1994, na Hungria em 1996, na Áustria em 1997 e na Coréia em 1998. Em compensação, a tendência atual é mais próxima da estabilidade.

Tabela 2: A evolução do emprego no setor público (milhares)

\begin{tabular}{l|r|r|r|l|c|c|c}
\hline País & 1990 & 1995 & $2000 *$ & País & 1990 & 1995 & $2000^{*}$ \\
\hline Austrália & 1.167 & 1.187 & 1.322 & Itália & -- & -- & 3.109 \\
\hline Áustria & 405 & 431 & 442 & Coréia & 818 & 905 & 869 \\
\hline Canadá & 2.663 & 2.649 & 2.582 & Nova Zelândia & 210 & 207 & 205 \\
\hline Dinamarca & 692 & 699 & 709 & Noruega & -- & -- & 134 \\
\hline Finlândia & 580 & 518 & 537 & Reino Unido & 5.267 & 3.674 & 3.477 \\
\hline França & 4.618 & 4.855 & 4.819 & Estados Unidos & 17.752 & 18.592 & 20.572 \\
\hline
\end{tabular}

* Ano mais recente para os dados que figuram nesta coluna: 1997 para a França; 1998 para a Dinamarca e a Noruega; 1999 para a Austrália, a Áustria, a Finlândia, a Itália e o Reino Unido. Os dados que se referem à Áustria, à Dinamarca e à Nova Zelândia correspondem ao equivalente do emprego de tempo integral.

Segundo os resultados do estudo sobre o emprego e a remuneração no setor público Public Sector Pay and Employment (PSPE), revela-se que, na maioria dos países-membros, o número de empregados das administrações centrais (ou federais) diminuiu ligeiramente nestes últimos anos, 
enquanto que aumentou o das administrações regionais e locais. Esta tendência confirma que os recursos para pagamentos de pessoal foram delegados nos pontos de serviço.

No entanto, as políticas de redução dos efetivos levantaram outras questões controvertidas, como a segurança do emprego para os empregados recrutados (programas pró-ativos de pedido de emprego, formação e bônus) e as restrições orçamentárias que restringiram a gama de serviços ou o tamanho da "rede de seguridade".

\section{Descentralização e flexibilidade da Gestão de RH}

\section{Descentralização e delegação}

Uma das principais reformas destes últimos anos refere-se à descentralização das responsabilidades da GRH, que antigamente eram atribuídas à administração central, para os ministérios e as agências administrativas. Esta descentralização foi igualmente acompanhada da delegação de responsabilidades aos quadros operacionais destas agências e ministérios. Esta transformação se apóia na hipótese básica que diz que é essencial responsabilizar e motivar os quadros para melhorar seus resultados no trabalho, deixando-os dirigir.

- É na Nova Zelândia, na Austrália e na Suécia que a delegação das responsabilidades de GRH foi mais marcante. Estas iniciativas visavam reduzir ao mínimo o envolvimento da administração central nas atividades de GRH garantidas pelas agências ou ministérios.

- Esforços de delegação importantes também aconteceram na Dinamarca, na Holanda e no Reino Unido, mesmo que sua abordagem tenha sido mais restrita que nos três países mencionados no parágrafo precedente.

- A descentralização e a delegação não aparecem como uma questão prioritária para alguns países, particularmente o Japão, a Grécia, Portugal e a Turquia.

\section{Área de descentralização e de delegação}

Nos países-membros, quais são as formas de autoridade de GRH que foram objeto de descentralização ou de delegação? Praticamente todas as formas de autoridade podem ser objeto de descentralização, seja através do recrutamento de novos empregados, da remuneração, da indicação, e também das relações de trabalho e das negociações salariais. No entanto, as áreas de descentralização variam de um país para o outro. 
A Suécia, que tem um longo passado de descentralização, é um dos países piloto que registraram o mais alto nível de descentralização entre os países-membros, em matéria de GRH. Os diretores-gerais das agências foram e permanecem incumbidos do recrutamento, da indicação e da demissão de seu pessoal. Eles podem contratar quem melhor lhes aprouver. Nenhuma "função pública" engloba o todo da administração. Os postos disponíveis são publicados na imprensa e todos os candidatos qualificados são tratados de forma igual. Não existe, na Suécia, o emprego vitalício. De fato, naquele país, não existe praticamente qualquer diferença entre a legislação de emprego que rege o setor público e a que rege o setor privado. Até mesmo os procedimentos de negociações coletivas, que eram a exceção marcante na descentralização, foram inteiramente confiados aos funcionários em 1994, e eles passaram, a partir de então, para a responsabilidade do diretor-geral de cada agência. As despesas de pessoal são, atualmente, uma das principais contas orçamentárias que o diretor-geral deve gerenciar, sem ultrapassar as alocações de crédito. ${ }^{5}$ Durante os anos 80 e 90, a Nova Zelândia e a Austrália foram objeto de reformas de descentralização análogas.

\section{Quadro 1: Legislação adotada em 1996 sobre as relações profissionais na Austrália}

De acordo com a legislação sobre relações profissionais adotada em 1996, os poderes públicos promoveram reformas que deram lugar à criação de um novo quadro de acordos profissionais. Este quadro prevê as modalidades e as condições de emprego a serem negociados entre os empregadores e os empregados, no nível das agências administrativas, sob a forma de acordos profissionais australianos (Australian Workplace Agreements - AWA ) e de acordos certificados (Certified Agreements - CA).

Ao mesmo tempo, os poderes públicos procuraram integrar as modalidades de emprego aos serviços públicos australianos (Australian Public Services - APS). As agências APS tiveram um papel importante para concluir os acordos profissionais possíveis pelas reformas nas relações do trabalho.

Os poderes públicos publicaram, em maio de 1997, os parâmetros estratégicos a serem aplicados no âmbito da conclusão de acordos profissionais nos serviços públicos australianos. Estes parâmetros, sempre protegendo os interesses do governo como último empregador, servem de modelo para delegar às agências o poder de concluir acordos profissionais.

\section{Papel da agência central de Gestão de RH}

A questão da descentralização e da delegação está estreitamente ligada ao papel da agência central de GRH. De fato, o papel da agência central diminuirá com a continuidade da descentralização dos poderes de 
GRH. Num contexto de descentralização e/ou de delegação, as agências centrais mantêm sua influência sobre a formulação das políticas. A tendência é claramente proporcionar flexibilidade aos quadros operacionais de ação, às orientações e às definições das normas básicas. Em tais estruturas, as agências administrativas e os ministérios dispõem de legislação própria em matéria de GRH e de uma maior liberdade para adaptar suas práticas às próprias necessidades de pessoal.

Em conseqüência, as áreas de aplicação de um sistema unitário através de todo o conjunto da função pública, englobam as despesas de pessoal (determinação da remuneração, efetivos, classificação dos empregos), os altos funcionários (modalidades e condições básicas do emprego e da gestão de pessoal), o comportamento e a disciplina, a saúde e a segurança e, finalmente, as políticas de igualdade de oportunidades. Mesmo para essas áreas, as agências administrativas e os ministérios parecem começar a dispor de uma maior flexibilidade. Por exemplo, são cada vez mais numerosos os países que substituem as verificações detalhadas das questões de pessoal por uma certa forma de gestão dos custos de funcionamento, que consiste em consolidar as despesas de remuneração e os custos administrativos. Esta nova prática elimina a necessidade, das agências centrais, de verificar detalhadamente as questões relativas aos efetivos, à classificação dos cargos e, em alguns casos, à remuneração. Por outro lado, na maioria dos países-membros, os governos confiaram uma grande parte das responsabilidades de GRH às agências administrativas e aos ministérios, particularmente nas áreas de seleção, de contratação de novos empregados, de planos de carreira e de mobilidade e distribuição de pessoal.

Na Holanda, por exemplo, em conseqüência da política de descentralização dos anos 90, boa parte dos poderes relativos às questões de pessoal foi delegada aos ministérios e aos gerentes operacionais, o que modificou consideravelmente o papel do Estado como empregador. Até 1993, o Ministro do Interior e das Relações do Reino era o único empregador da administração central. A partir de então, o ministro foi substituído por oito "empregadores" distintos, cada um representando um setor específico. Como conseqüência desta modificação, partes da GRH continuam centralizadas, sob a supervisão da agência central de GRH, mas as questões de pessoal específicas, que se apresentam todos os dias são resolvidas por serviços descentralizados. Isto se refere, particularmente, aos seguintes assuntos:

- o sistema de indicação de classificação;

- os sistemas de remuneração no quadro das negociações do escalão central;

- as aposentadorias e a previdência social; 
- as condições de emprego;

- a obrigação de empregar uma certa proporção de "grupos especiais" e de manter um justo equilíbrio entre os empregados de ambos os sexos.

\section{Flexibilidade e a liberdade em matéria de gestão}

A flexibilidade do sistema de Gestão de RH é atingida quando se encontra o justo equilíbrio entre o tipo de função pública que o governo deseja consolidar ou manter — ou seja, a função pública centralizada e o controle no nível central com relação à delegação de poderes de decisão e de gestão - e às metas de performance orçamentária. Por mais que a descentralização permita dar flexibilidade aos sistemas e práticas de Gestão de RH, ela não garante sempre uma grande flexibilidade. Em alguns paísesmembros que delegaram uma grande parte dos poderes de GRH às agências administrativas, revelou-se que um bom número destas agências e dos ministérios não dispunha de sistemas suficientemente flexíveis, e que um grande número deles usava sistemas de gestão análogos àqueles da administração central.

\section{Garantir a responsabilização dos quadros e da organização}

\section{Incentivar os funcionários a conseguir um bom rendimento ou bons resultados no trabalho}

Em troca da delegação de poderes de GRH aos ministérios temáticos e aos quadros operacionais, vários países-membros envidaram esforços para assegurar um comportamento responsável por parte das organizações e de seus quadros. Para tanto, alguns países optaram pela melhoria dos resultados funcionais em nível de organização e individual. $\mathrm{Na}$ escala de organização, os países introduziram sistemas de gestão baseados em resultados ou no rendimento do trabalho, que enfatizam as metas ou objetivos da organização. Em nível individual, os resultados se tornam um aspecto muito importante da GRH. Vários países tentaram, particularmente, estabelecer uma conexão entre a remuneração, na função pública, e os resultados ou os rendimentos do empregado.

Vários programas foram implantados, mas eles diferem em seu modo de aplicação.

- A Islândia adotou, depois de ter conseguido chegar a um acordo com o sindicato dos empregados públicos sobre os aumentos salariais por tempo de serviço, uma tabela de remuneração flexível e detalhada a fim de recompensar os resultados individuais. 
- A Suíça e o Reino Unido também estão entre os países que dispõem de uma tabela de remuneração flexível que recompensa os resultados do empregado.

- Por seu turno, a Alemanha, a Áustria, a Coréia e os Estados Unidos, para atrair os trabalhadores, optaram por ajustar os salários de acordo com a demanda do mercado ou as necessidades em matéria de especialistas.

- Outros países, particularmente a Bélgica e a Hungria, buscam suprimir o abismo que existe entre os setores público e privado.

\section{Melhorar a deontologia (tratado dos deveres) na função pública}

Os titulares de um cargo público não eleitos exercem um poder discricionário considerável em seus deveres quotidianos: na sua boa gestão dos recursos públicos, em seus relacionamentos com os cidadãos e na elaboração da política. As normas éticas são indispensáveis ao bom equilíbrio dos poderes, a fim de impedir seu uso arbitrário. Esta observação é particularmente verdadeira nas situações de descentralização e de delegação dos poderes de GRH onde é indispensável assegurar a responsabilidade dos funcionários. Neste sentido, a ética no serviço público tornou-se um tema de grande importância na maioria dos países da OCDE. O estudo da OCDE sobre este tema agrupa as abordagens adotadas pelos paísesmembros para desenvolver a deontologia em três grandes categorias, ou seja:

- o quadro jurídico;

- a convivência profissional;

- a criação de um ambiente profissional.

A abordagem ligada ao quadro jurídico. Vários países assumem os valores éticos do quadro dos regulamentos existentes, por exemplo, promovendo emendas ou instituindo uma nova legislação. Diversos países adotaram leis destinadas a melhorar a transparência e a redefinir os limites ligados aos conflitos de interesse. Por exemplo, a Itália e o Japão adotaram leis sobre informação ao público, que obrigam os altos funcionários a declarar seus bens pessoais. Da mesma forma, alguns países dispõem de leis que tratam de uma interface político/administrativa, como a Polônia e a Itália, ou uma interface entre os setores público/privado, como o emprego de funcionários do setor privado do Japão.

A abordagem ligada à convivência profissional. A socialização profissional pela realização de seminários, de estágios, de formação ou de difusão de publicações, constituiu uma outra abordagem, geralmente adotada pelos países-membros. Por exemplo, o Japão dá a seus empregados instruções claras no que diz respeito aos procedimentos estritos e honestos que seriam seguidos se eles viessem a agir de forma errada. Na Dinamarca, 
a administração publicou uma obra sobre a ética, que suscitou a abertura de um debate nacional.

A abordagem ligada à criação de um ambiente profissional. Criar um ambiente no qual os empregados respeitem as regras, se sintam no direito de exprimir suas queixas e trabalhem usando ao máximo seus potenciais, constitui uma outra abordagem importante. A Alemanha recompensa aqueles que cooperam em pesquisas relativas aos atos de corrupção, e a Austrália assegura a proteção das pessoas que apontem atos corruptos. A Suíça favorece uma cultura corporativista. A Finlândia revisou os critérios e os procedimentos de seleção dos altos funcionários, aumentando a concorrência para estes postos.

Algumas as tendências comuns que foram destacadas dos diversos enfoques adotados pelos países-membros. ${ }^{7}$

- Mais de um terço dos países-membros já reformulou os valores fundamentais do serviço público ao longo dos últimos cinco anos, e outras revisões estão em curso em alguns países. Na hora da reformulação, os países sublinharam novamente a importância dos valores "tradicionais", tais como a imparcialidade, a legalidade e a integridade, mas, ao mesmo tempo, dando-lhes um significado moderno e adicionando "novos" valores, a saber, a transparência e a eficiência, pondo, assim, em evidência, uma cultura do serviço público baseada, cada vez mais, na qualidade dos resultados.

- Em segundo lugar, a definição jurídica das normas de conduta tornou-se o principal meio de explicar, em detalhes, os valores fundamentais que foram enunciados. Quase todos os países-membros definiram com maior precisão as normas que são esperadas de todos os funcionários públicos, nas situações que possam dar lugar a conflitos de interesse, em particular com relação a: 1) o uso das informações oficiais e dos serviços públicos; 2) a aceitação de presentes e de vantagens; e 3) o uso no exterior dos serviços públicos. Fora as normas gerais de conduta, que todos os funcionários públicos têm a obrigação de observar, os países-membros fazem uso de diretrizes complementares que se aplicam a categorias profissionais específicas. Estas dizem respeito às áreas particularmente sensíveis ou fortemente expostas a um conflito de interesse.

- A terceira característica diz respeito ao fato de que quase todos os países-membros atribuem alta prioridade à aplicação da deontologia, através da formação e de outros instrumentos, a fim de sensibilizar os funcionários públicos com relação à ética. Em mais da metade dos países-membros, uma grande importância é atribuída à comunicação dos valores aos funcionários públicos recentemente empregados e, em um terço dos países, uma declaração destes valores também é incluída no contrato de emprego.

- Finalmente, a última tendência que emana dos países-membros é no sentido de que a importância atribuída à prevenção de condutas pouco 
éticas comece substituir a repressão, reduzindo, assim, a necessidade de sanção. A prevenção é um investimento menos caro, a longo termo, e ela conduz a uma atitude mais positiva sobre a cultura do serviço público e sobre as relações entre o serviço público e a sociedade civil.

\section{Preservar o Estado como "empregador modelo"}

Enquanto o setor público efetuava reformas no sentido da redução dos efetivos, os governos tentavam preservar sua imagem de "empregador modelo". Em comparação com as empresas privadas, os poderes públicos atribuíram uma grande importância à igualdade de oportunidades de emprego, sem discriminação em função do sexo, de se pertencer a grupos minoritários ou de deficiências físicas. Como empregador modelo, o Estado, em alguns países, estipulou em suas leis o objeto do emprego destas pessoas. Em outros países, o Estado introduziu condições de trabalho flexíveis, como por exemplo o trabalho de tempo parcial, o trabalho em domicílio e os horários flexíveis de trabalho, a fim de incentivar os grupos desfavorecidos a trabalhar para o governo.

Poucos trabalhos são conclusivos quanto à boa reputação do Estado como empregador. Porém, a comparação do emprego feminino nos setores público e privado demonstra uma vantagem em benefício das mulheres no setor público. Esta observação confirma, indiretamente, os esforços que continuam a ser empreendidos pelos governos para serem considerados empregadores modelos.

\section{Figura 1: A porcentagem do emprego feminino na função pública no conjunto da economia}

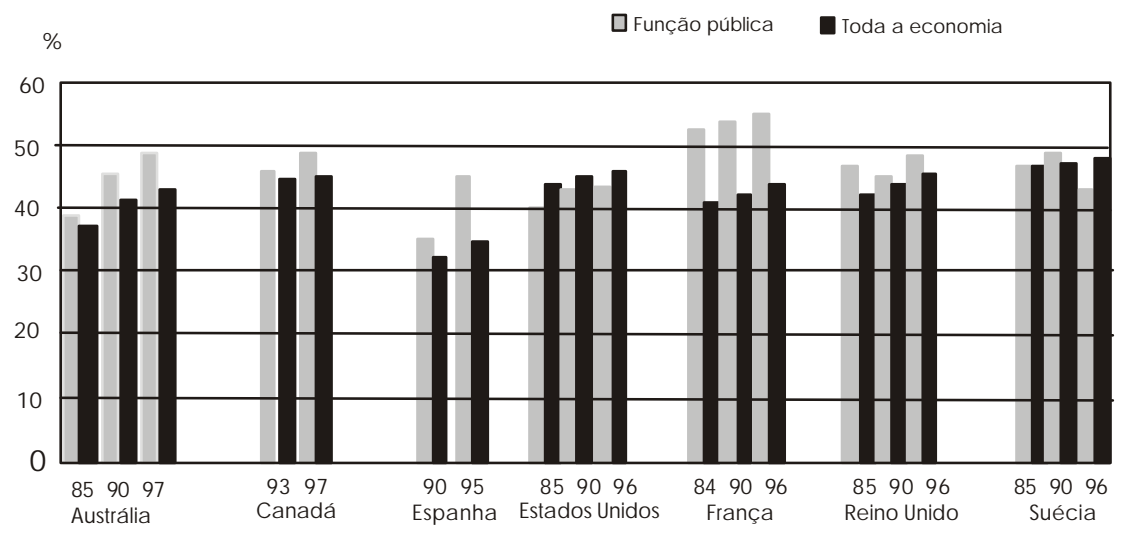


De acordo com a análise piloto ${ }^{8}$ efetuada pela OCDE, o número de mulheres empregadas no serviço público progrediu de forma nítida ao longo da última década. Em particular, como ilustra a Figura 1, as mulheres são sensivelmente mais numerosas no setor público do que em toda a economia, salvo nos Estados Unidos. Na Austrália, no Canadá, na Suécia, no Reino Unido e nos Estados Unidos, a diferença entre os dois setores é moderada, enquanto ela é bastante significativa na França e na Espanha. A taxa de representação das mulheres no setor público é de aproximadamente 50\% na Austrália, no Canadá e no Reino Unido, mas ela ultrapassa a taxa dos homens na França (56,3\% em 1996). Apesar da progressão do efetivo feminino na função pública, a proporção de mulheres que ocupam postos executivos ou de responsabilidade ainda é relativamente baixa.

Afora estas evoluções da reforma sobre a GRH, nós podemos extrair outras tendências comuns a vários países da OCDE:

- a expansão do emprego sob contrato para diversos cargos de altos funcionários;

- os programas de formação e de aperfeiçoamento dirigidos aos quadros superiores, a fim de assegurar que a população ativa continue a ter a flexibilidade, as aptidões e as competências necessárias.

- a difusão, no setor público, de certas técnicas de gestão do desempenho no trabalho, aperfeiçoadas pelo setor privado (por exemplo, a avaliação de resultados e sistemas de bônus);

- os procedimentos de racionalização para dar fim aos empregos, da mesma forma que os procedimentos de apelação e de administração de conflitos, são elementos da reforma de GRH que foram aplicados em vários países, mesmo que pareça mais difícil efetuar mudanças nesta área.

\section{Incidências das reformas passadas e os novos desafios}

\section{Incidências da reforma da GRH}

É muito difícil avaliar as iniciativas de reforma anteriores, relativas à GRH, levando-se em conta o pouco tempo que se passou e também a ausência de critérios de avaliação. É por isso que nenhuma avaliação exaustiva foi efetuada sobre as atividades recentes das reformas levadas a cabo em todos os países-membros. No entanto, vários países que se esforçaram por implementar reformas importantes de GRH, assinalaram que estas iniciativas tinham contribuído para a substituição da cultura de gestão regulamentada pela cultura de gestão baseada nos resultados.

Vários países tiveram a impressão de que as políticas de descentralização e de delegação contribuíram para: 
- desenvolver formas de gestão e de organização mais eficazes e eficientes;

- melhorar a qualidade geral dos serviços prestados ao público;

- melhorar as motivações e os resultados do trabalho (particularmente os resultados dos dirigentes); e

- incentivar os funcionários públicos a serem mais eficientes.

Ficou evidente que as reformas de GRH que eram acompanhadas de incidências mais marcantes favoreciam maiores mudanças no seio da organização, particularmente:

- encorajando uma maior diversidade de práticas de GRH entre os diferentes ministérios e agências, e fornecendo os meios necessários à adaptação destas práticas às necessidades específicas em programas;

- permitindo aos ministérios e às agências empregar e manter, mais facilmente, o pessoal necessário e dirigir seus efetivos com maior eficiência, possibilitando atender os objetivos de sua organização;

- estimulando o poder de iniciativa dos dirigentes, tornando-os mais responsáveis e permitindo-lhes agir de uma maneira mais pró-ativa;

- insistindo mais na eficiência e na eficácia, o que causa resultados positivos na prestação de serviços e na receptividade do pessoal.

Por mais que estas novas orientações tenham sido acompanhadas de efeitos secundários, os países-membros não exprimiram nenhum desejo de renunciar às reformas de descentralização e de delegação; ao contrário, eles estão se empenhando, atualmente, em responder às necessidades de implantação de mecanismos visando reforçar a coordenação e a responsabilidade de quadros que favorecem as práticas e os valores desejados em todo o conjunto do serviço público.

\section{Novos desafios que se colocam para a Gestão de $\mathbf{R H}$}

Apesar das contribuições mencionadas acima, as reformas recentes em GRH suscitaram algumas inquietudes. Em primeiro lugar, à medida em que se atenuavam as diferenças da GRH entre os setores público e privado, os funcionários públicos perdiam alguns de seus privilégios em matéria de segurança do emprego, de condições de trabalho e de estatuto. Por outro lado, o seu nível de remuneração não progrediu em nada em relação a seus homólogos do setor privado. É por esta razão que vários países-membros se defrontam com dificuldades para empregar e conservar pessoal de alta qualidade. A isto vem se adicionar um mercado de trabalho mais rígido, devido aos períodos sucessivos de aquecimento econômico ao longo destes últimos anos. A administração pública está, portanto, perdendo sua vantagem competitiva em matéria de recrutamento. Em alguns países, os jovens funcionários altamente qualificados tendem a renunciar ao setor 
público e a se fazer empregar por empresas privadas. Este fenômeno é atualmente um novo desafio para a maioria dos países da OCDE.

A descentralização, em geral, dificulta a coesão da função pública e a coerência das políticas. Ela também desestimula o esprit de corps no serviço público, levando à perda de unidade de um programa que busca o bem comum. A constituição de um corpo homogêneo de funcionários públicos que compartilhe os mesmos valores e seja engajado será outro desafio que os países-membros deverão levar em consideração. Vários países criaram a categoria "alta função pública" para melhorar a integração das administrações. Por exemplo, a Holanda introduziu, em 1995, a rede da alta função pública (SPS), a fim de constituir uma reserva geral de funcionários para alimentar uma equipe de altos dirigentes capazes de melhorar o profissionalismo, a qualidade e a integridade da função pública. O desenvolvimento da capacidade de direção também é uma questão pela qual vários países se interessam muito.

A internacionalização e a introdução de novas tecnologias de informação e de comunicação dominam o discurso atual sobre a GRH. Atualmente, a melhor gestão destes recursos se caracteriza por uma maior facilidade de acesso à informação e ao conhecimento, no interior de uma organização e de uma organização para outra. Ela se caracteriza, também, por uma maior integração dos funcionários no seio de sua unidade de trabalho, a fim de otimizar a coordenação das funções que eram, até agora, autônomas. Em troca, as distinções hierárquicas e funcionais entre os diferentes tipos de emprego foram atenuadas. Para fazer frente a este novo ambiente, a maioria dos países-membros começou a atribuir uma grande importância à melhoria no uso das TICs e da gestão do conhecimento. Esta melhoria se traduzirá no reforço das capacidades dos funcionários públicos e na melhoria dos resultados da organização.

Por outro lado, uma das questões novamente abordadas na GRH diz respeito à igualdade dos sexos. Como empregadores modelos, os governos de vários países exprimem há um bom tempo suas inquietudes a este respeito. No entanto, ainda restam vários desafios a serem enfrentados para tratar os homens e as mulheres em condições de igualdade.

\section{O surgimento de novas questões relativas à GRH com o começo do século XXI}

O começo do século XXI é acompanhado de numerosos desafios à gestão pública. Novos conceitos de gestão pública apareceram para tirar melhor proveito das novas oportunidades, tais como a tecnologia da informação, vencer desafios cruciais, como o envelhecimento de nossas populações, ou simplesmente reduzir os efeitos das reformas anteriores. 
Com vistas a vencer estes novos desafios, a OCDE começou a interessarse, em seus trabalhos, por questões que tratam, em particular, dos meios de se contratar e de conservar pessoal altamente qualificado na função pública, das estratégias de desenvolvimento da capacidade de direção e da consolidação da capacidade de gestão do conhecimento.

\section{Desenvolvimento da capacidade de direção no setor público}

Os países-membros estimam, de maneira geral, que existe um abismo entre o setor público atual e os interesses presentes e futuros de sua nação. Em todos os países, a reforma da gestão e da reestruturação do setor público permitiu melhor adaptar os serviços públicos às necessidades da sociedade contemporânea. Mas, após a implementação destas reformas e da análise de seus resultados, os países-membros constatam que ainda existe um gap entre a cultura das administrações públicas e o interesse geral. Em que consiste este gap? Uma queixa que aparece constantemente é quanto à falta de empenho da parte dos funcionários em respeitar os valores fundamentais do serviço público e em servir aos interesses dos cidadãos. Como resolver essa questão? Uma conclusão muito recorrente mostra a necessidade de se promover o desenvolvimento de certas capacidades de direção. Estas capacidades são, em particular, um elemento indispensável à boa administração pública, tema importante dos trabalhos atuais da OCDE.

\section{Um empregador público competitivo}

A maioria dos países-membros se defronta com um problema sério de escassez de competências no setor público. Este problema resulta, em alguns países, das mutações demográficas que aconteceram nestes últimos anos, em particular o envelhecimento da população. Se os países atravessam diferentes fases de mutação demográfica, uma parte importante dos empregados do setor público vai pedir sua aposentadoria nos próximos dez anos. Outros países sinalizaram que este problema emana da falta de competitividade das administrações públicas com relação ao setor privado para empregar e manter empregados qualificados. Será cada vez mais difícil para o setor público empregar trabalhadores competentes em razão da competitividade crescente do setor privado que atrai e mantém os indivíduos mais qualificados. As remunerações mais baixas, a perda de prestígio e a execução de afazeres banais levaram vários jovens diplomados, assim como altos funcionários, a escolher uma carreira no setor privado em detrimento do setor público. 


\section{A gestão do conhecimento}

Os países-membros estão impacientes para implementar um tipo de programa de gestão do conhecimento, Knowledge Management (KM), mas eles não dispõem, no momento, da experiência ou do conhecimento para fazê-lo. $\mathrm{O}$ estudo do caso dinamarquês extrai três objetivos principais no quadro da gestão do conhecimento, os quais são: 1) o desenvolvimento de uma nova informação; 2) a utilização de informações existentes; 3) a organização e a gestão da informação. $\mathrm{O}$ estudo distingue dois tipos de conhecimento; um é relacionado ao que o indivíduo aprendeu através de sua experiência e sua formação, e passa pelo diálogo; a outra forma se compõe de textos escritos, como os resultados de pesquisa, os dados e a imprensa, e ela é codificada. O desafio que deve vencer a GRH é de criar sistemas de gestão do conhecimento $(K M)$ que favoreçam, ao mesmo tempo, a expansão do conhecimento e a utilização que ele faz destes dois domínios.

\section{As mulheres dirigentes no setor público}

À medida em que os países-membros dedicam um interesse cada vez maior à igualdade dos sexos, eles se dão conta de que a questão das dirigentes femininas na função pública aparece como uma das áreas importantes, embora menos estudadas, da GRH. Segundo o estudo da OCDE, ${ }^{9}$ são raros os países que mencionam a questão das mulheres dirigentes na função pública. A Noruega abordou esta questão fixando um plano quadrienal com vistas a aumentar em $22 \%$, em 1997, e em 30\%, em 2001, o número de mulheres que ocupam cargos de direção superior e intermediário. Apesar do aumento da proporção de mulheres na função pública, como foi mencionado no começo desta seção, parece que o número de mulheres que ocupam cargos de direção executivos e de responsáveis ainda é relativamente baixo.

\section{A integração da GRH às outras questões mais gerais de administração}

A GRH é um dos instrumentos de gestão mais eficazes para melhorar a eficiência e o rendimento no setor das administrações públicas. A melhoria da GRH, em áreas como a dos métodos de remuneração e de emprego, métodos de trabalho, a cultura organizacional e a satisfação profissional, permitirá às organizações de serviço público serem mais eficazes e eficientes. A integração desta forma de gestão a outros instrumentos de gestão, em particular a condução, a qualidade, a programação orçamentária e a contabilidade da instituição, terá um efeito sinérgico. Se examinarmos um exemplo de reforma implementada num determinado país, constataremos que as relações entre a GRH e os outros instrumentos de gestão são sempre muito limitadas. Esta outra questão deverá ser objeto de estudo no futuro. 
Texto traduzido sob a responsabilidade da ENAP Escola Nacional de Administração Pública das edições originais em inglês e francês, sob os títulos: Developments on Human Resources Management in OECD Member Countries e Développements Récents de la Gestión de Ressources Humaines dans les Pays Membres de l'OCDE[PUMA/ HRM(2001)5/FINAL]. Copyright OECD, 2001. A OECD não se responsabiliza pela qualidade da tradução em português e sua coerência com o texto original. Reunião do Grupo de Trabalho sobre Gestão de Recursos Humanos, Paris, 25-26 Junho 2001.

Os mecanismos de tipo comercial evocam todos os arranjos que comportam pelo menos uma característica importante dos mercados (concorrência, escolha, cálculo dos preços, tomadas de decisões descentralizadas, incentivos monetários, e assim por diante). Eles excluem os dois casos extremos, a saber: a prestação de serviços tradicionais pelas administrações públicas e a privatização completa.

Na Holanda, esta tendência foi qualificada de "normalização", um dos dois principais elementos das reformas da GRH. A normalização supõe a atenuação das diferenças históricas entre o setor público e o setor privado, abolindo as regras uniformes da administração central sobre as condições de trabalho dos funcionários.

3 Para maiores informações sobre os resultados do estudo, consultar o relatório da OCDE [PUMA/HRM(99)3] - "A evolução da Gestão dos Recursos Humanos nas administrações públicas".

4 Trata-se dos correios e das telecomunicações, das ferrovias, do serviço de Imprensa Nacional, do Instituto Nacional Geográfico, do Serviço Público de Restauração e do Centro Nacional de Processamento de Dados.

5 OCDE (2001), Revista da OCDE sobre a administração orçamentária, volume 1, número 1.

6 São eles a administração central, a defesa, a educação, o Judiciário, a polícia, as municipalidades, as províncias e as companhias de água.

OCDE (2000), "Reforçar a ética no serviço público: as medidas dos países da OCDE."

OCDE, [PUMA/HRM(2000)7], "Resumo da análise dos dados da base de dados PSPE (emprego e remunerações no setor público) e futuros desenvolvimentos da coleta de dados", documento apresentado na Reunião do Grupo de Trabalho sobre a GRH que ocorreu em julho de 2000.

9 OCDE [PUMA/HRM(2000)6], "Desenvolvimentos recentes e desafios futuros da gestão dos recursos humanos nos países-membros da OCDE", documento apresentado na Reunião do Grupo de Trabalho sobre a GRH que ocorreu em julho de 2000. 


\section{Desenvolvimentos recentes da gestão dos recursos humanos nos países membros da OCDE \\ Serviço de Gestão Pública \\ Comitê de Gestão Pública - PUMA/OCDE}

As reformas da administração pública, nas duas últimas décadas, tiveram como principal objeto a gestão dos recursos humanos.

O artigo descreve as evoluções das reformas de gestão de recursos humanos nos países membros da OCDE estabelecendo uma conexão entre as reformas anteriores e os desafios atuais. Aponta que apesar das diferentes estratégias e da variação da amplitude das mudanças adotadas pelos diversos países, pode-se afirmar que a busca da eficiência, da ética, da transparência, da melhoria da qualidade dos serviços públicos e o enxugamento da máquina administrativa foram pontos comuns em quase todas as reformas.

\section{Desarollos recientes de la gestión de los recursos humanos en los países miembros de la OCDE \\ Servicio de Gestión Pública \\ Comité de Gestión Pública - PUMA/OCDE}

Las reformas de la administración pública, en las dos últimas décadas, tuvieran como principal objeto la gestión de los recursos humanos.

El artículo describe las evoluciones de las reformas de gestión de recursos humanos en los países miembros de la OCDE establecendo una conección entre las reformas anteriores y los desafíos actuales. Apunta que a pesar de las diferentes estratégias y de la variación de la amplitud de las mudanzas adoptadas por los diversos países, es posible afirmar que la búsqueda de la eficiencia, de la ética, de la transparencia, de la mejoría de la calidad de los servicios públicos y el enjuagamiento* de la máquina administrativa fueran puntos comunes en cuasi todas las reformas.

\section{Recent developments in human resource management in OECD member countries}

Public Management Service

Public Management Committee - PUMA/OECD

The public administration reforms in the last two decades were mainly focused on human resource management (HRM).

The article describes the HRM developments in OECD member countries, setting a connection between previous reforms and current challenges. It points out that despite the different strategies and the amplitude variation of changes implemented in many countries, there were common points in most of the reforms, such as the seek for efficiency, ethics, transparency, downsizing and improvement of public services.
Revista do

Serviço

Público

Ano 52

Número 2

Abr-Jun 2001

Organização

para a

Cooperação e o

Desenvolvimento Econômico (OCDE), Paris, França. 